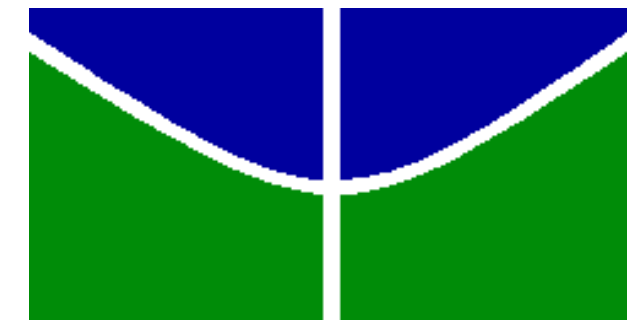

UNIVERSIDADE DE BRASÍLIA

Faculdade de Educação - UAB/UnB/MEC/SECAD

Curso de Especialização em Educação na Diversidade e

Cidadania, com Ênfase em Educação de Jovens e Adultos - EJA

Dinarte Miguel de Oliveira

Márcia Regina Simões Giovani

O problema da Evasão Escolar na Educação de Jovens e Adultos no Centro Educacional do Lago e no Centro de Ensino Médio Setor Leste

BRASÍLIA, DF

Julho/2010 


\author{
UNIVERSIDADE DE BRASÍLIA \\ Faculdade de Educação - UAB/UnB/MEC/SECAD \\ Curso de Especialização em Educação na Diversidade e \\ Cidadania, com Ênfase em EJA
}

\title{
O problema da Evasão Escolar na Educação de Jovens e Adultos no Centro Educacional do Lago e no Centro de Ensino Médio Setor Leste
}

\author{
Dinarte Miguel de Oliveira \\ Márcia Regina Simões Giovani \\ Elizabeth Danziato Rego \\ Professora Orientadora \\ Airan Almeida de Lima \\ Tutor Orientador \\ PROJETO DE INTERVENÇÃO LOCAL
}

BRASÍLIA, DF Julho/2010 


\author{
UNIVERSIDADE DE BRASÍLIA \\ Faculdade de Educação - UAB/UnB/MEC/SECAD \\ Curso de Especialização em Educação na Diversidade e \\ Cidadania, com Ênfase em EJA
}

Dinarte Miguel de Oliveira

Márcia Regina Simões Giovani

\title{
O problema da Evasão Escolar na Educação de Jovens e Adultos no Centro Educacional do Lago e no Centro de Ensino Médio Setor Leste
}

Trabalho de conclusão do Curso de Especialização em Educação na Diversidade e Cidadania, com Ênfase em EJA, como parte dos requisitos necessários para obtenção do grau de Especialista na Educação de Jovens e Adultos.

Elizabeth Danziato Rego

Professora Orientadora

Airan Almeida deLima

Tutor Orientador

Hélvia Leite Cruz

Avaliador Externo

BRASÍLIA, DF Julho/2010 


\section{RESUMO}

Este projeto tem como finalidade conhecer as causas da evasão escolar de alunos do Centro Educacional do Lago e do Centro de Ensino Médio Setor Leste, 3ำ segmento (Educação de Jovens e Adultos - EJA) de Brasília - Distrito Federal. A metodologia utilizada para isso será a pesquisa qualitativa e a quantitativa. Após identificar suas possíveis causas, pretende-se refletir sobre estratégias pedagógicas a serem implementadas nas respectivas escolas. Será necessário organizar grupos de estudo com professores da EJA com a finalidade de questionar quais as causas da evasão e apontar soluções por meio de ações que serão debatidas com os alunos. Constata-se, com a vivência como docentes, a necessidade de a sociedade tentar diminuir a evasão escolar, que mais do que nunca apresenta-se de forma tão ampliada e complexa. Deve-se desenvolver trabalhos educativos, visando a consolidação da aprendizagem, voltados para qualificação dos alunos. Buscase também, que os mesmos possam melhorar seus níveis de conhecimento científico, trabalhando com várias áreas de pesquisa. Portanto, escola e aluno deverão concentrar seus esforços no sentido de tentar minimizar este problema, e com isso o aluno terá a possibilidade de não evadir, obtendo assim sucesso escolar, pessoal e profissional.

PALAVRAS-CHAVE: Educação de Jovens e Adultos - evasão escolar - metodologia - aprendizagem significativa. 


\section{LISTA DE GRÁFICOS}

Gráfico 1 - Evasão escolar no Centro Educacional do Lago - EJA - Matutino 2008/2009 ................12

Gráfico 2 - Evasão Escolar no Centro Educacional do Lago - EJA - Noturno 2008/2009..................12

Gráfico 3 - Evasão Escolar no Centro de Ensino Médio Setor Leste - EJA 2008/2009.....................13 


\section{SUMÁRIO}

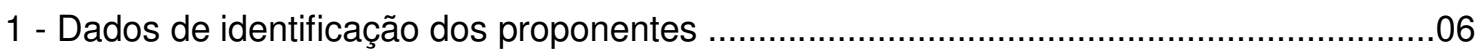

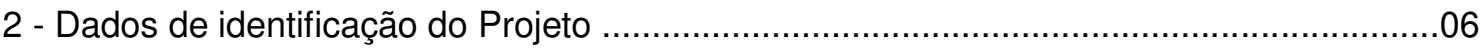

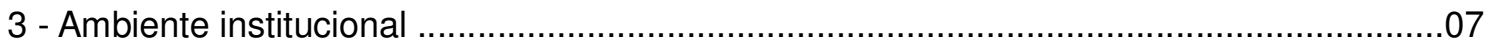

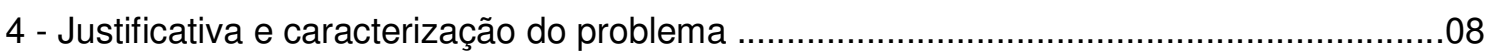

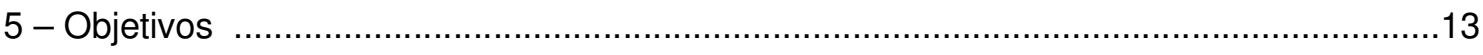

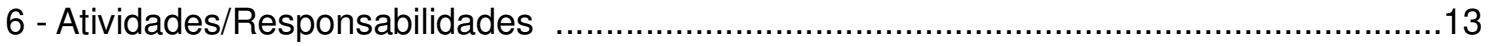

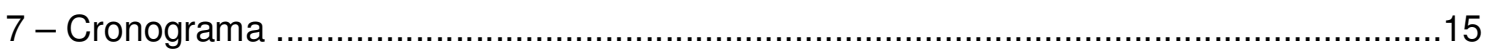

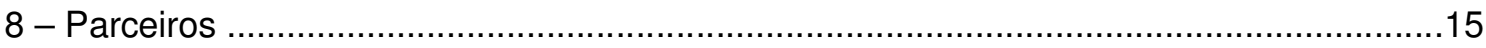

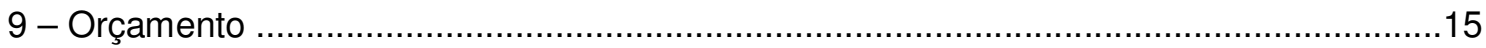

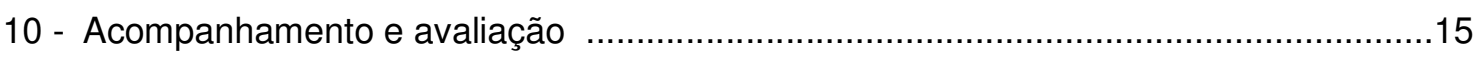

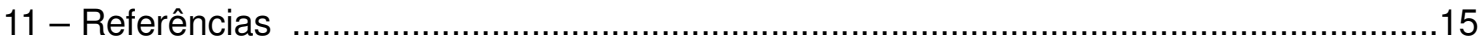

12 - Apêndice 


\section{DADOS DE IDENTIFICAÇÃO DOS PROPONENTES}

Professores da Secretaria de Educação do Distrito Federal que atuam na Regional do Plano Piloto/ Cruzeiro com Educação de Jovens e Adultos.

\subsection{NOMES:}

Márcia Regina Simões Giovani

Dinarte Miguel de Oliveira

1.2 TURMA: E - Polo de Santa Maria-DF

1.3 INFORMAÇÕES PARA CONTATO:

mrsgiovani@gmail.com/ 32570749/ 9138-7733

dinartemiguel2@yahoo.com.br 30220126/8181-2541

\section{DADOS DE IDENTIFICAÇÃO DO PROJETO}

2.1 TÍTULO - O problema da Evasão escolar na Educação de Jovens e Adultos no Centro Educacional do Lago e no Centro de Ensino Médio Setor Leste.

\section{2 ÁREA DE ABRANGÊNCIA}

Local

2.3 INSTITUIÇÕES

- Centro Educacional do Lago

QI 9 Área Especial, Lote $\mathrm{H}$ - Lago Sul

Brasília - DF. Tel.: 3901-2635 CEP 71625-009

- Centro de Ensino Médio Setor Leste

SGAS 611/612 . CEP 70200-710

Brasília - DF. Tel. 39017602

INSTÂNCIA INSTITUCIONAL:

Governo do Distrito Federal

Secretaria de Educação do Distrito Federal

Conselho de Educação do Distrito Federal

Direção do Centro Educacional do Lago e do Centro de Ensino Médio Setor Leste DF.

\subsection{PÚBLICO AO QUAL SE DESTINA}

O projeto é destinado aos alunos do $3^{\circ}$ segmento da EJA do Centro Educacional do Lago e do Centro de Ensino Médio Setor Leste, que são moradores da Asa Sul, Lago Sul, São Sebastião, Paranoá e adjacências.

\subsection{PERÍODO DE EXECUÇÃO}

Início: julho de 2010

Término: dezembro de 2010. 


\section{AMBIENTE INSTITUCIONAL}

Centro Educacional do Lago e Centro de Ensino Médio Setor Leste

\subsection{HISTÓRICO DO CENTRO EDUCACIONAL DO LAGO}

O Centro Educacional do Lago - CEL localiza-se num bairro de classe A, Lago Sul, Brasília. Foi inaugurado em 1979 onde funcionava o Ginásio do Lago- GILA. Entretanto, a demanda observada neste local demonstrou a necessidade de implantar uma escola pública, sendo então esta a primeira de Ensino Médio desse bairro. Com o passar dos anos e o crescimento das comunidades de São Sebastião e Paranoá, que careciam de uma escola de Ensino Fundamental, o GILA foi transformado em Centro Educacional do Lago, passando a oferecer Ensino Fundamental, Ensino Médio e Educação de jovens e adultos. Assim a escola passou a atender também, alunos de várias cidades satélites.

A Secretaria de Estado de Educação do Distrito Federal vem implementando, nos últimos anos, reforma em toda a rede escolar. Com a construção e melhoria das escolas públicas nas próprias cidades satélites alguns alunos de baixa renda se transferiram para as escolas de suas cidades, enquanto outros de classe média passaram a freqüentar o CEL (cerca de 20\%).

O CEL neste ano tem a oferecer à comunidade as seguintes séries:

- Turno matutino: $1^{\circ}, 2^{\circ}$ e $3^{\circ}$ anos do ensino médio e correção de fluxo escolar do ensino médio, antigo Projeto Vereda e $3^{\circ}$ segmento da EJA.

- Turno vespertino: $7^{a}$ e $8^{a}$ séries (ensino fundamental) e Correção de Fluxo Escolar das séries finais do ensino fundamental, antigo Projeto Vereda.

- Turno noturno: $1^{\circ}, 2^{\circ}$ e $3^{\circ}$ anos do ensino médio e $1^{\circ}$ e $2^{\circ}$ segmentos da EJA.

O CEL é uma escola inclusiva e no período da tarde tem alguns alunos especiais.

\subsection{HISTÓRICO DO CENTRO DE ENSINO MÉDIO SETOR LESTE}

O Centro de Ensino Médio Setor Leste integra a estrutura organizacional da Secretaria de Estado da Educação do Distrito Federal e está subordinado pedagógica e administrativamente à Diretoria Regional do Plano Piloto/ Cruzeiro - DRE-PP/C. Seu prédio foi construído no início dos anos 60 e funciona como escola do ensino médio regular desde 1963.

O Setor Leste oferece aos alunos da Asa Sul e adjacências o $1^{\circ}, 2^{\circ}$ e $3^{\circ}$ anos do ensino médio nos três turnos, $7^{a}$ e $8^{\underline{a}}$ séries do ensino fundamental no turno vespertino, duas turmas de EJA, matutino e vespertino no $3^{0}$ segmento e turmas de aceleração. Entretanto, é muito frequentado por alunos oriundos de diversas cidades satélites, como Valparaíso, Luziânia, Cidade Ocidental, Novo Gama. 


\section{JUSTIFICATIVA E CARACTERIZAÇÃO DO PROBLEMA}

Nos últimos anos, nas escolas públicas do DF, existia um número grande de alunos repetentes que cursavam o ensino regular e havia desistência de alguns que não terminavam o ensino médio. Os professores reclamavam que não tinham como baixar mais o nível de ensino para fazer com que estes alunos conseguissem aprovação no ano letivo e concluíssem a escolarização. Tornou-se desafiador para o professor a tarefa de manter o aluno na escola. Daí surgiu a necessidade de implantar um Projeto de Aceleração.

Várias pesquisas foram feitas para tentar descobrir as causas da evasão escolar, chegando-se à conclusão de que a falta de interesse pela escola é o principal motivo do problema. A pesquisa, Motivos da Evasão Escolar, lançada em 2009 pela Fundação Getúlio Vargas - FGV-RJ mostra que 40\% dos jovens de 15 a 17 anos deixam de estudar simplesmente porque acreditam que a escola é desinteressante. A necessidade de trabalhar é apontada como o segundo motivo pelo qual os jovens abandonam a escola, com $27 \%$ das respostas, e a dificuldade de acesso à escola aparece com 10,9\%. A pesquisa acima citada só confirmou outras anteriores de 2004 e 2006, também da FGV.

Levando esse dado em consideração, a Fundação Roberto Marinho desenvolveu um projeto com o nome de Projeto Vereda que era implantado na própria escola onde já funcionava o ensino regular. Esse novo modo de ensino identificou-se com a EJA e teve início em 2008, quando então foi dado ao aluno fora de idade/ série, e com alto índice de repetência, a oportunidade de fazer parte deste projeto.

O Projeto Vereda tem uma metodologia diferente das aulas tradicionais que utilizam o quadro negro como ferramenta didática. Nele, as aulas são ministradas por meio de mídias, o que faz com que estas sejam muito mais interessantes. O material didático também colaborou com a eficácia do projeto, visto que os alunos recebem livros coloridos e ilustrados que tentam dinamizar o processo de aprendizagem.

Essa metodologia foi implantada no CEL e no Setor Leste no ensino fundamental e médio, contemplando alunos da EJA do $2^{\circ}$ e $3^{\circ}$ segmentos. Ela, com efeito, diminuiu os índices de evasão escolar, mas não satisfatoriamente. Afinal, a pesquisa da FGV - RJ mostra que o desinteresse é o principal motivo da evasão escolar de jovens entre 15 e 17 anos, mas a EJA contempla alunos de todas as idades, acima de 15 anos.

Daí surge a necessidade de se efetuar pesquisas com alunos da Educação de Jovens e Adultos, objetivando obter informações para evitar o fenômeno da evasão escolar no sistema de ensino de jovens e adultos no CEL e no Setor Leste, compreendendo os problemas e causas do abandono escolar.

CAMPOS (2003) ao citar FONSECA (2002, p. 5) em sua tese de mestrado, afirma que, "os motivos para o abandono escolar podem ser ilustrados quando o jovem e adulto deixam a escola para trabalhar; quando as condições de acesso e segurança são precárias; os 
horários são incompatíveis com as responsabilidades que se viram obrigados a assumir; evadem por motivo de vaga, de falta de professor, da falta de material didático; e também abandonam a escola por considerarem que a formação que recebem não se dá de forma significativa para eles".

Deve-se entender quais os motivos que levam os alunos a serem infrequentes, como também se suas expectativas trazem relação com o compromisso de se manterem frequentes nos cursos em que se matricularam.

SANTOS M. A. (2007, p.5) fez um estudo sobre a permanência de jovens e adultos no ambiente escolar. Ela afirma que "é importante pensar o trabalho pedagógico da EJA de forma que o educando participe do desenvolvimento da sociedade. Sendo assim, nós enquanto educadores temos a responsabilidade de criarmos uma dinâmica metodológica que atinja o interesse do educando, de maneira que a escola recupere seu objetivo social e supere o fracasso escolar e a repetência".

Pode-se destacar vários fatores que interferem na sua permanência escolar, dentre eles a sobrecarga de trabalho extensivo, aspectos relacionados com a complexidade da vida pessoal, familiar, financeira e laboral; professores sem uma qualificação adequada ao programa para jovens e adultos que tem contribuído mais para a exclusão social do que para a formação educacional. Acredita-se que muito mais importante que repassar conhecimento, é desenvolver no aluno a capacidade de aprender. Isso redefine o papel da escola.

Assim, nosso objetivo deve ser formar indivíduos que possam aprender e que sejam ativos na busca da informação, utilizando como ferramentas básicas a filosofia,a matemática e outras línguas, além de seu próprio idioma, que é a base para a formação da cidadania; a matemática o capacita a operar o pensamento abstrato aplicado na prática; desenvolver a linguagem falada e escrita permite ao educando expressar suas idéias com mais eficácia e entender melhor aquilo que ouve, enquanto o aprendizado de línguas estrangeiras o auxilia a lidar com outras sociedades e outros valores, aproximando-o do mundo globalizado.

Quando um aluno abandona a escola, deixa de usufruir de toda essa aprendizagem que decorre da educação. No sentido mais amplo, a educação exerce influência no meio social sobre os indivíduos e estes, ao assimilarem essas influências, estabelecem uma relação ativa e transformadora com o meio social.

No atual contexto social, a escola surge de forma dinâmica, como espaço de construção e reconstrução do conhecimento, como articuladora do processo natural de desenvolvimento das pessoas e do seu meio.

Assim como regem os Parâmetros Curriculares Nacionais e as Orientações Curriculares da Secretaria de Estado de Educação, Ensino Médio e Fundamental, a educação, na prática, deverá criar condições necessárias para o exercício pleno da 
cidadania, desenvolvendo as capacidades e a apropriação dos conteúdos necessários para a compreensão da realidade e a participação nas relações sociais, políticas e culturais.

O Centro Educacional do Lago e o Centro de Ensino Médio Setor Leste busca envolver o aluno no processo ensino-aprendizagem, considerando-o responsabilidade dos professores e da administração da escola, buscando oportunidades de vivenciar a solidariedade e diminuir a evasão.

Por isso necessário se faz rever alguns pontos deste sistema de ensino para jovens e adultos, que necessita de uma avaliação tanto entre as metodologias aplicadas, como também os motivos que estão contribuindo para o crescimento da repetência e evasão escolar.

A evasão escolar sempre mobilizou a atenção das instituições de ensino em seus diversos níveis. Na Educação de Jovens e Adultos esta realidade tem alguns agravantes, uma vez que os estudantes normalmente já estão comprometidos com o trabalho, não julgam a escolaridade como algo tão importante em suas vidas e o motivo que os leva a retornar aos estudos é na maioria das vezes questões de ordem prática (maior chance de concorrer a vagas no mercado de trabalho ou receberem uma promoção no cargo em que ocupam).

As melhorias na educação não acontecem de imediato, mas ao longo do processo. Definições e objetivos devem ser bem planejados para que as conquistas de conclusão das etapas pedagógicas sejam alcançadas, caso contrário, antes de completar um ciclo o mesmo é modificado ou trocado por outro para atender aos anseios particulares do aluno.

Necessário se faz, portanto, desenvolver ações efetivas que consigam minimizar esta situação e o primeiro passo neste sentido é conhecer as causas reais porque estes jovens abandonam a escola com frequência e reincidência.

Só a partir da resposta em questão é possível redirecionar a prática pedagógica desta modalidade com clientela da mais diversa e determinar ações até mesmo estruturais, que possam garantir a permanência destes estudantes até a conclusão do curso.

De acordo com FREIRE (1991, p. 37) "É nesta perspectiva de emancipação do sujeito, que a educação deve ser usada como prática de liberdade, afinal, ninguém liberta ninguém, ninguém se liberta sozinho, os homens se libertam em comunhão".

Pode-se observar que a sociedade pode mudar o sistema das instituições de ensino devido suas necessidades e anseios; mas o que se vê é que ela não despertou para tal problema, continuando sem ação diante do alto índice de evasão nas escolas.

Passa-se de uma situação menor para nível do Distrito Federal e pode-se ver que a implantação de política da EJA foi devido à grande quantidade de pessoas acima de 15 anos, que não concluía o Ensino Fundamental, sem falar no Ensino Médio. A EJA busca entender esses trabalhadores e desempregados que chega num total de 600.000 pessoas, 
conforme informação do Gerente da Educação de Jovens e Adultos da Secretaria de Educação do Governo do Distrito Federal , José Edilson Rodrigues da Fonseca. Ao observar o levantamento dos últimos anos, percebe-se que deste total apenas 60.000 faz matrícula todos os anos e um terço, ou seja, 20.000 conseguem concluir os estudos de ensino médio ou equivalente.

Observa-se que com a iniciativa da Secretaria de Educação em servir lanche nas escolas, nos últimos meses houve uma mudança significativa na frequência dos alunos do período noturno do CEL. Esta mudança também pode ser justificada pelo fato de a passagem do transporte coletivo ter passado a ser gratuita.

A questão do lanche nos mostra que os sujeitos da EJA noturno, em sua maioria, são alunos de baixa renda e a do transporte evidencia que muitos deles também residem distante de onde estudam. Alguns deles são moradores de cidades periféricas, como Paranoá e São Sebastião e eles estão inseridos num contexto que não condiz com a realidade deles. Outros moram no Lago Sul e trabalham nas casas do entorno, em diversas profissões como motoristas, jardineiros, caseiros, empregadas domésticas, babás e outras.

Já no período matutino os alunos têm um perfil diferenciado dos alunos do noturno. Muitos moram em São Sebastião e no Paranoá, Jardim ABC, nos condomínios e no Lago Sul. Estudam no CEL neste período pessoas de várias classes sociais, inclusive pessoas que já estudaram em conceituadas escolas de Brasília. Daí decorre uma diversidade econômica e cultural que pode ser uma das causas de evasão e outra é o fato de o aluno residir distante de onde estuda. Assim, é importante que uma pesquisa seja feita nesse sentido.

Da mesma forma que ocorre no CEL os alunos do Setor Leste, em sua maioria, residem distante de onde estudam. São moradores de várias regiões administrativas do Distrito Federal e de algumas cidades do entorno, tais como Valparaízo de Goiás, Luziânia, Cidade Ocidental e Novo Gama, alguns são filhos de Funcionários Públicos que chegaram a ter acesso a escolas particulares e devido ao mau desempenho migram para a escola pública por desistência dos pais de arcarem com ônus financeiro. Devido ao fato de os pais trabalharem no Plano Piloto, preferem colocar seus filhos na escola pública mais próxima do seu trabalho.

Segundo os alunos das escolas citadas, eles preferem a escola longe de casa porque as mesmas têm mais qualidade do que as de suas cidades.

O CEL e o Setor Leste, apesar de serem escolas distintas, têm características muito semelhantes em se tratando de alunos que residem em um lugar e estudam em outro. Até que ponto o aluno residir longe da escola pode vir a ser causa da evasão escolar?

Segundo CAMPOS (2003) a evasão escolar na EJA pode ser registrada como um abandono por um tempo determinado ou não. Diversas razões de ordem social e 
principalmente econômica concorrem para a "evasão" escolar dentro da EJA, transpondo a sala de aula e indo além dos muros da escola.

\section{GRÁFICOS E ANÁLISE DE DADOS}

Evasão escolar no Centro Educacional do Lago - EJA - Matutino

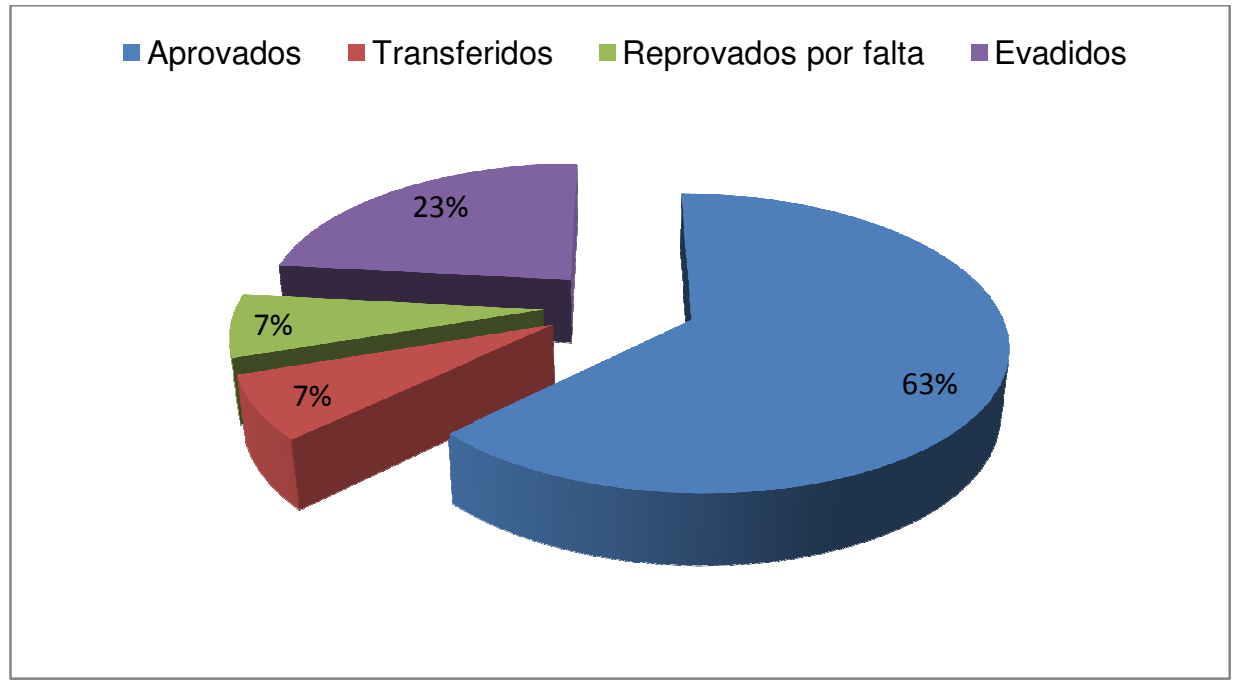

Gráfico 1 - Evasão escolar no Centro Educacional do Lago - EJA - Matutino 2008/2009 Fonte: Secretaria da escola. Dados relacionados ao quantitativo de 43 alunos.

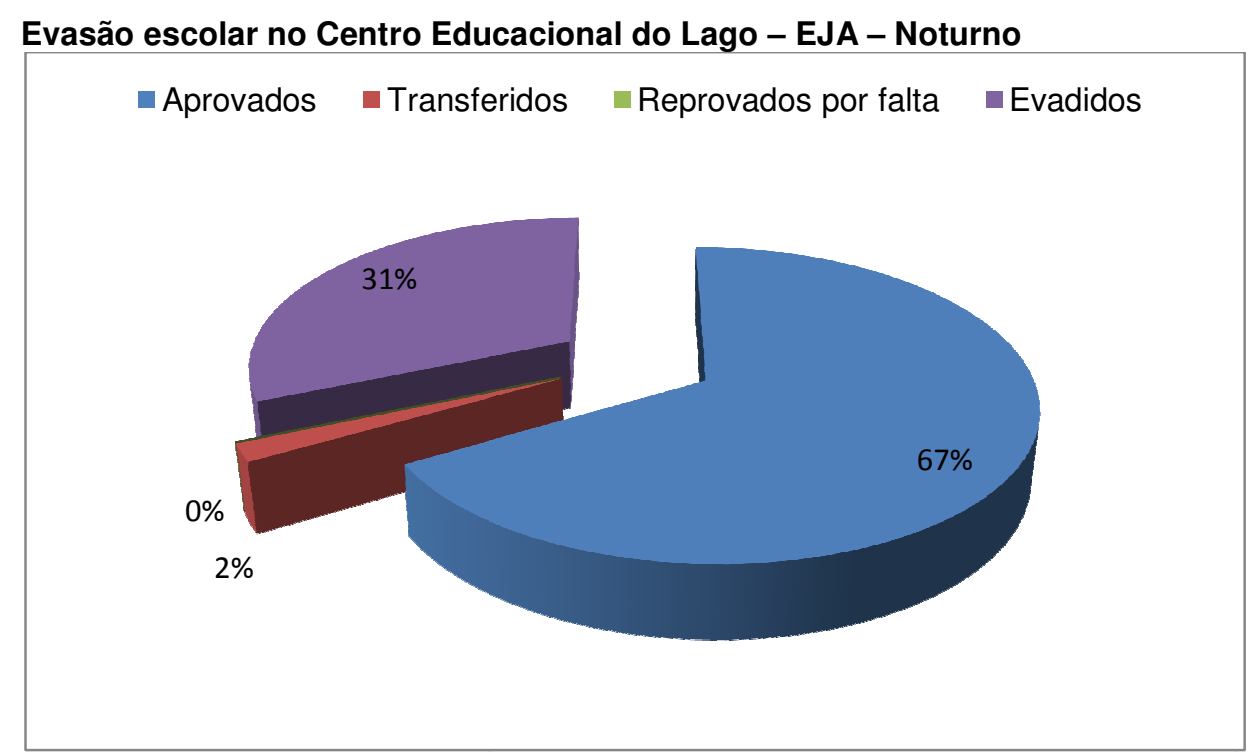

Gráfico 2 - Evasão Escolar no Centro Educacional do Lago - EJA - Noturno 2008/2009 Fonte: Secretaria da escola. Dados relacionados ao quantitativo de 54 alunos. 
Evasão Escolar no Centro de Ensino Médio Setor Leste - EJA

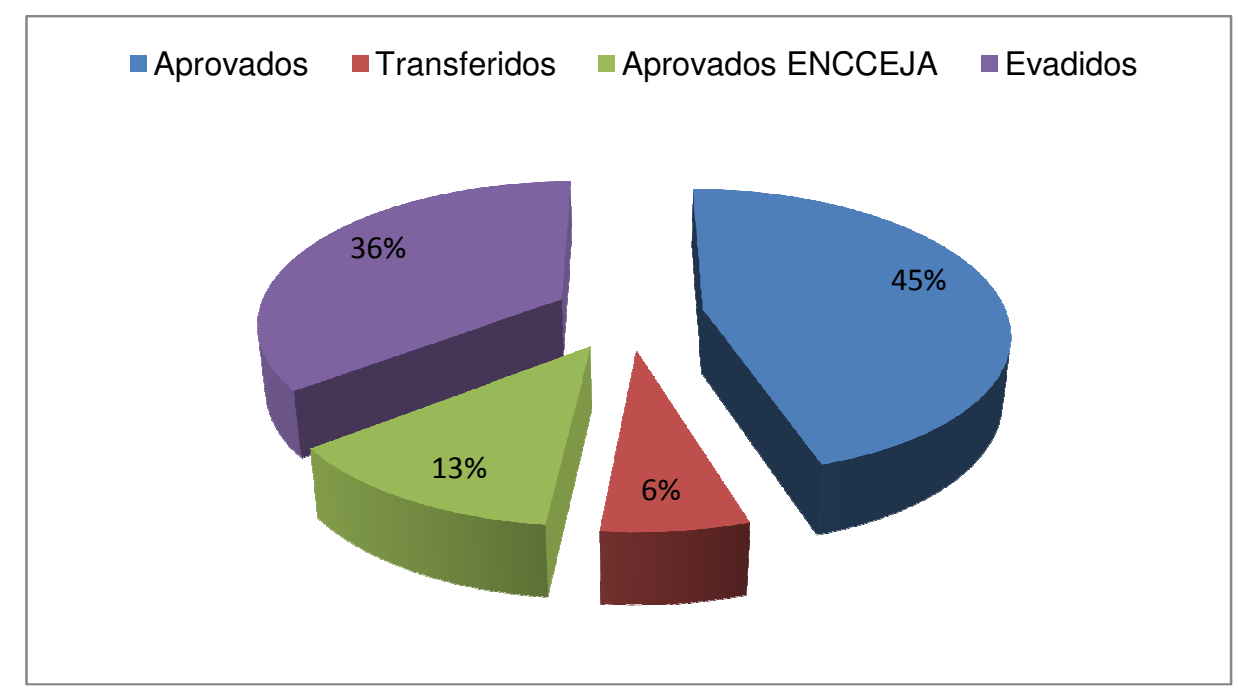

Gráfico 3 - Evasão Escolar no Centro de Ensino Médio Setor Leste - EJA 2008/2009

Fonte: Secretaria da escola. Dados relacionados ao quantitativo de 62 alunos.

Os gráficos mostram a realidade de 2008 e 2009 do índice de evasão escolar da EJA nas escolas citadas. Acredita-se que este índice de evasão está alto, sendo necessário que diminua nos próximos anos. Verifica-se que o índice de evasão do CEL, noturno, é maior que a do diurno por serem aqueles, sujeitos trabalhadores e com realidade de vida diferente dos alunos do diurno. Já no Setor Leste o índice de evasão foi maior do que no CEL, mesmo se tratando de um curso do período diurno.

\section{OBJETIVOS}

\subsection{OBJETIVO GERAL}

Realizar pesquisa com alunos da EJA do Centro Educacional do Lago e do Centro de Ensino Médio Setor Leste com vistas ao desenvolvimento de ações que minimizem o índice de evasão escolar.

\subsection{OBJETIVOS ESPECÍFICOS}

- Identificar as causas atuais da evasão escolar na visão dos alunos, para oferecer subsídios para sua redução;

- Criar espaço para sondagem das expectativas dos alunos da EJA;

- Apresentar recomendações à equipe da escola para replanejar suas ações junto aos alunos da EJA;

- Desenvolver ações que possibilitem a permanência do aluno na escola.

\section{ATIVIDADES/ RESPONSABILIDADES}

O projeto de combate à evasão escolar será estruturado com base no diagnóstico da situação local. 
Identificado o problema, parte-se para frente de ação. Terão que ser utilizados dois tipos de abordagens: uma local com contato direto com os alunos nas referidas escolas, que se resume em conversas juntamente com a orientadora educacional( sobre reestruturação das orientações curriculares para EJA e conteúdo das disciplinas escolares) até as adaptações dos alunos para a transição das séries. A outra seria a divulgação do projeto e a sensibilização da comunidade escolar com relação ao problema da evasão.

As atividades a serem desenvolvidas no projeto serão:

- Planejar e desenvolver todos os passos para a aplicação do questionário;

- Realizar novas pesquisas qualitativas, por meio de entrevistas com os alunos, para sanar possíveis dúvidas em relação às suas respostas no questionário;

- Fazer reuniões semanais com a direção, coordenação, professores da EJA e orientadores educacionais para analisar os dados obtidos no questionário, com tempo previsto para cada reunião de aproximadamente 90 minutos;

- Saber como a outra escola está reagindo durante o desenvolvimento do projeto, comparando dados das duas escolas;

- Propor à direção das escolas mudanças pedagógicas direcionadas para cada uma delas em particular, com vistas a diminuir os índices de evasão escolar;

- Realizar novas pesquisas quantitativas junto à secretaria das escolas para avaliar os novos dados de evasão, após implementação de mudanças.

Cada profissional desempenhará um papel importante no projeto:

Professores - aplicarão o questionário e acompanharão o resultado da pesquisa;

Coordenadores - apresentarão recomendações à equipe e organizarão os debates; participarão da aplicação do questionário.

Direção da escola - fornecerá materiais para serem utilizados durante o desenvolvimento do projeto;

Orientador educacional - atenderá individualmente os alunos no que tange à autoestima e ao rendimento dos mesmos. 


\section{CRONOGRAMA 2010}

\begin{tabular}{|c|c|c|}
\hline Atividades & Pessoas envolvidas & Mês \\
\hline Elaboração do projeto & Márcia e Dinarte & $\begin{array}{l}04,05 \text { e } \\
06\end{array}$ \\
\hline $\begin{array}{ll}\text { Elaboração do } & \text { duestionário }\end{array}$ & Márcia e Dinarte & 05 \\
\hline $\begin{array}{l}\text { Desenvolvimento do } \\
\text { projeto }\end{array}$ & $\begin{array}{l}\text { Márcia, Dinarte, diretores, supervisores, orientadores educacionais, } \\
\text { professores, coordenadores pedagógicos }\end{array}$ & 07 a 12 \\
\hline $\begin{array}{ll}\text { Aplicação } & \text { do } \\
\text { questionário } & \end{array}$ & Márcia, Dinarte, alunos, professores, coordenadores & 07 \\
\hline $\begin{array}{l}\text { Tabulação do } \\
\text { questionário }\end{array}$ & Márcia e Dinarte & 08 \\
\hline
\end{tabular}

\section{PARCEIROS}

Participam deste projeto de combate à evasão escolar a direção da escola, coordenadores, Serviço de Orientação Educacional, professores regentes do Ensino de Jovens e Adultos, alunos e Secretaria da Educação.

\section{ORÇAMENTO}

Os recursos deste projeto serão fornecidos pela própria escola.

\section{ACOMPANHAMENTO E AVALIAÇÃO}

O projeto será desenvolvido de julho a dezembro de 2010, por meio de aplicação de questionário, análise de resultados/dados, entrevistas com alunos e confecção de gráficos. O questionário será aplicado aos alunos de EJA do Centro Educacional do Lago e do Centro de Ensino Médio Setor Leste, da Rede Pública de Ensino do Distrito Federal, que avaliará as causas da evasão escolar e as questões teóricas e metodológicas da EJA.

Pode-se afirmar que é necessário criar grupos de estudos com todos os formadores, objetivando questionar as causas da evasão na tentativa de buscar soluções de urgência, através de ações que devem ser discutidas com o educando a respeito do programa da EJA e sua importância no desenvolvimento integral do cidadão. Além disso, também é necessário a elaboração de um currículo que atenda às expectativas dos alunos, com inovação de prática, dentro de uma didática renovada e motivadora, que possa elevar a autoestima dos estudantes, dando sentido significativo aos seus valores sócio-cultural e histórico, no qual eles estão inseridos.

\section{REFERÊNCIAS}

CAMPOS, Edna Lúcia Ferreira; OLIVEIRA D. A. A Infrequência dos alunos adultos trabalhadores, em processo de alfabetização, na Universidade Federal de Minas Gerais. 
2003. Dissertação (Mestrado em Educação) - Faculdade de Educação, Universidade Federal de Minas Gerais, Belo Horizonte, 2003.

SANTOS, Maria Aparecida Monte Tabor. A produção do sucesso na educação de jovens e adultos: o caso de uma escola pública em Brazlândia. 2007. Dissertação (Mestrado em Educação) - Faculdade de Educação, Universidade de Brasília, Brasília, 2007.

FREIRE, Paulo. Educação como prática de liberdade: a sociedade brasileira em transição. Rio de Janeiro, Paz e Terra, 1991.

LEI DE DIRETRIZES E BASES DA EDUCAÇÃO NACIONAL - Da educação de jovens e adultos - 9.394/96 - LDB - seção $V$, art 37 , parágrafos $1^{\circ}$ e $2^{\circ}$.

\section{APÊNDICE}

\subsection{QUESTIONÁRIO}

Prezado(a) aluno(a), este questionário tem como finalidade ajudar a descobrir as causas da evasão em nossa escola. Contamos com a sua colaboração para que juntos possamos fazer deste estabelecimento de ensino um ambiente melhor. Responda as questões abaixo com a maior sinceridade possível para trabalharmos com os resultados obtidos.

Este questionário será aplicado a todos os alunos do 3ํ. segmento da EJA.

A) Qual a sua idade?

a.1 - de 18 a 20 anos.( )

a.2 - de 21 a 25 anos.( )

a.3 - de 26 a 30 anos.( )

a.4 - de 31 a 35 anos.( )

a.5 - de 36 a 40 anos.( )

a.6 - mais de 40 anos.( ) 
B) Qual motivo te levou a abandonar os estudos? Marque mais de um item caso necessário.

b.1 - Necessidade de trabalhar;( )

b.2 - Motivos de saúde;( )

b.3 - Gravidez não planejada;( )

b.4 - Falta de apoio familiar; ( )

b.5 - Dificuldade de aprendizagem;( )

b.6 -Outros.( )

C) Quantas vezes você interrompeu seus estudos?

c.1 - Uma vez;( )

c.2 - Até três vezes;( )

c.3 - Mais de três vezes.( )

D) O que te motivou a voltar a estudar?

d.1 - Necessidade de ampliar os conhecimentos para dar segmento aos estudos;( )

d.2 - Facilidade de acesso ao mercado de trabalho;( )

d.3 - Conseguir promoção no trabalho;( )

d.4 - Outros.( )

E) Como você avalia a importância de concluir o Ensino Médio?

e.1 - Muito importante;( )

e.2 - De menor importância;( )

e.3 - Não tem a menor importância;( ) 
F) O que você gostaria que mudasse na EJA para que as aulas te despertassem maior interesse?

f.1 - O modo como são dadas as aulas;( )

f.2 - Mais utilização da mídia (vídeos, CDs);( )

f.3 - Aulas no laboratório de informática;( )

f.4 - Outros( )

G) Na sua opinião, esse curso da EJA deve sofrer alguma modificação?

( ) Sim ( ) Não

Qual?

H) Qual a área você tem mais dificuldade?

h.1 - Códigos e linguagens;( )

h.2 - Matemática e suas ciências tecnológicas;( )

h.3 - Ciências da natureza.( ) 